\title{
Reversible Depression in Myocardial Performance in Dogs with Experimental Phosphorus Deficiency
}

\author{
Thomas J. Fuller, Wilmer W. Nichols, Bruce J. Brenner, and John C. Peterson, \\ Veterans Administration Hospital, Gainesville, Florida 32602; and \\ Divisions of Renal Medicine and Cardiology, Department of Medicine, \\ University of Florida, Gainesville, Florida 32610
}

\begin{abstract}
A B S T R A C T The effects of phosphorus depletion on cardiac muscle function in six awake dogs were evaluated with surgically implanted transducers to serially measure ascending aortic root blood flow and high fidelity left ventricular pressure. After the animals recovered from surgery, phosphorus depletion was induced by feeding them a synthetic phosphorusdeficient diet plus aluminum carbonate gel for 35 days, followed by the same diet with phosphorus supplementation for 21 days. In addition to the cardiac studies, sequential measurements of phosphorus content in skeletal muscle and phosphorus in serum were obtained to ascertain the level of phosphorus depletion.
\end{abstract}

Serum inorganic phosphorus concentration $(\mathrm{mg} / 100$ $\mathrm{ml}$ ) decreased from $5.1 \pm 0.1$ on day 0 to $0.9 \pm 0.1$ on day $35(P<0.01)$, and total muscle phosphorus (content $\mathrm{nmol} / 100 \mathrm{~g}$ fat-free dry weight) decreased from 28.0 \pm 0.2 on day 0 to $22.6 \pm 0.5$ on day $35(P<0.01)$. During the period of phosphorus depletion, there was no significant change in heart rate; however, stroke volume (milliliter) and peak blood flow velocity (centimeter per second) declined from $24 \pm 2$ to $17 \pm 2(P<0.01)$ and $121 \pm 12$ to $98 \pm 7(P<0.01)$, respectively. Maximum ascending aortic blood flow acceleration (centimeter per second square) and maximum left ventricular time rate of change of pressure $(\mathrm{mm} \mathrm{Hg}$ per second) also decreased from $4,630 \pm 313$ to $3,817 \pm 346(P<0.01)$ and $2,582 \pm 347$ to $2,120 \pm 297(P<0.01)$ during phosphorus depletion. After repletion all values returned to control values.

These results indicate that moderate diet-induced phosphorus depletion can depress myocardial perfor-

Address reprint requests to Dr. Fuller, Renal Division, Box J224, J. Hillis Miller Health Center, University of Florida, Gainesville, Fla. 32610.

Dr. Fuller is a Veterans Administration Research Associate.

Received for publication 21 July 1977 and in revised form 17 July 1978. mance. With repletion of phosphorus, myocardial performance improves.

\section{INTRODUCTION}

Chronic phosphorus depletion has been associated with various functional and structural derangements in experimental animals and in man. These derangements include decreased hepatic oxygenation and abnormalities of liver function (1), cerebral dysfunction (2), erythrocyte rigidity and hemolysis (3), impaired phagocytosis by leukocytes (4), platelet dysfunction.(5), and renal tubular defects (6).

Studies have shown that phosphorus depletion has an adverse effect on skeletal muscle function and composition (7-9). Specifically, a symptom complex characterized by muscle stiffnes, weakness, and severe pain has been described in patients taking antacids containing aluminum hydroxide. These complaints were especially notable when serum phosphorus concentrations decreased to $\cong 1 \mathrm{mg} / 100 \mathrm{ml}$ and improved rapidly with correction of the hypophosphatemia $(7,8)$. In addition, selective phosphorus depletion in experimental animals is characterized by a low resting transmembrane electrical potential difference, as well as changes in skeletal muscle composition consistent with a "sick" cell (9).

O'Connor and colleagues (10) have recently suggested that hypophosphatemia or phosphorus depletion or both may also have a deleterious effect on cardiac function. Their studies, however, were performed on critically ill patients who manifested, in addition to phosphorus depletion, a variety of toxic, metabolic, and nutritional derangements. As a result, the explicit role of phosphorus depletion in their findings cannot be ascertained.

We therefore investigated the effects of selective dietary-induced phosphorus depletion and repletion on cardiac muscle function in awake dogs by serially measuring high fidelity left ventricular pressure and 
aortic root blood flow. Peak velocity and maximum acceleration of blood ejected from the left ventricle (11) and the maximum rate of rise of left ventricular pressure (Max $d P / d T$ ) (12) were used to assess the contractile state of the myocardium.

\section{METHODS}

Six healthy adult, heartworm-free, male dogs, weighing 16-23 $\mathrm{kg}$, were used in the study. A left thoracotomy was performed under aseptic conditions, using a general anesthetic (halothane). The ascending aorta was isolated and an appropriately sized electromagnetic flow probe installed (Biotronex Laboratory, Inc., Silver Spring, Md.) by the technique outlined by Khouri (13). A calibrated solid state, high fidelity pressure transducer (Konigsberg Instrument, Inc., Pasadena, Calif.) was inserted into the left ventricle at the apex, using the procedure described by Stone (14). The leads of the two transducers were externally placed at the back of the neck between the scapulae; the chest was closed and the animal allowed to recover.

With the dogs awake, ascending aortic blood flow and left ventricular pressure were recorded on magnetic tape (model 3960, Hewlett-Packard Co., Waltham, Mass.), beginning after a postsurgical recovery period of 14 days and then weekly for the duration of the study. During the recovery period, the animal was taken to the laboratory daily and trained to lie quietly for at least $30 \mathrm{~min}$.

Phosphorus depletion was induced over a 35-day period after surgical recovery by feeding the animals $20 \mathrm{~g} / \mathrm{kg}$ of a synthetic phosphorus-deficient, but otherwise nutritionally adequate, diet. Each $450 \mathrm{~g}$ contained $90 \mathrm{~g}$ protein, $270 \mathrm{~g}$ carbohydrate, and $45 \mathrm{~g}$ fat (ICN Nutritional Biochemicals Div., International Chemical and Nuclear Corp., Cleveland, Ohio). They were also given aluminum carbonate gel (Basaljel, extra strength, Wyeth laboratories, Philadelphia, $\mathrm{Pa}$.), $60 \mathrm{~cm}^{3} /$ day. On chemical analysis, each $450 \mathrm{~g}$ of this diet contained $117 \mathrm{mg}$ of elemental phosphorus and $160 \mathrm{meq}$ of potassium. During the period of postsurgical recovery and during the 3-wk period of repletion, the same synthetic diet was used except that phosphorus was added as $\mathrm{Na}_{2} \mathrm{HPO}_{4}$ to provide a total elemental phosphorus intake of $1.87 \mathrm{~g} /$ day.

Measurement of blood flow velocity and acceleration. Aortic blood flow velocity was measured with a sine-wave electromagnetic flowmeter (model BL-613, Biotronex Laboratory, Inc.) and flow probes with various inside diameters (16-20 mm). For phasic flows, the flowmeter was operated at its highest nominal frequency setting (100), which gave a constant amplitude response within $\pm 5 \%$ from 0 to $47 \mathrm{~Hz}$ and a linear-phase shift. Zero flow was taken as the flat portion of the curve during late diastole, and mean flow was obtained by electrical integration of the curve. Stroke volume was obtained by dividing mean aortic blood flow by heart frequency (beats per second).

The flow probes were calibrated in vitro using physiological saline and a section of aorta. Calibration factors for each probe were determined before implantation and at the end of the study after the dog had been sacrificed. The calibration factors remained essentially constant throughout the period of the study. The flowmeter was calibrated in units of velocity by dividing the flow calibration by the aortic cross-sectional area. This was calculated from the external aortic diameter (D) measured when the flow probe was implanted, and from the presumed thickness of the aortic wall (H), derived from the formula $\mathrm{H}=0.075 \mathrm{D}$ (15). Peak blood flow velocity was obtained from the maximum value of the measured volume flow curve using the velocity calibration.
Maximum blood flow acceleration (the maximum rate of change of blood flow velocity) was obtained in two ways. (a) The maximum slope of the initial upstroke of the blood flow velocity curve was measured directly from a fast polygraph (Electronics for Medicine, Inc., White Plains, N. Y.) tracing $(100 \mathrm{~mm} / \mathrm{s})$ of the flowmeter signal. (b) A continuous record of acceleration was obtained by electrical differentiation of the phasic velocity signal. The differentiator (model BL-620, Biotronex Laboratory, Inc.) was operated at a nominal frequency setting (80), which gave a constant amplitude response within $\pm 5 \%$, from 0 to $35 \mathrm{~Hz}$. The differentiated velocity signal (acceleration) was then displayed along with the flow signal on a polygraph recording (Fig. 1). The differentiator was calibrated by correlating the peak differential with the graphically determined slope of the velocity signal at a fast paper speed $(100 \mathrm{~mm} / \mathrm{s})$. At least six sequential flow complexes were used for the calibration.

Measurement of left ventricular pressure and its derivative. High fidelity left ventricular pressure was obtained from the implanted strain gauge transducer (Fig. 1). Resonant frequencies of these gauges are generally $>1 \mathrm{kHz}$ (16). This frequency response is well in excess of that required to obtain dynamic left ventricular pressure and its derivative $(d P / d T)$ (17). The pressure transducers were precalibrated at $38^{\circ} \mathrm{C}$, and the sensitivity did not change during the study. Because these transducers are likely to drift during implantation, absolute pressure levels were not recorded. The rate of change of left ventricular pressure $(d P / d T)$ was obtained by electrical differentiation of the ventricular pressure signal. The dynamic frequency response of the differentiator was flat $\pm 5 \%$, from 0 to $43 \mathrm{~Hz}$. The continuous recording of $d P / d T$ (Fig. 1) was calibrated in the same manner as the blood flow acceleration.

Procurement and analysis of samples of skeletal muscle. After the cardiac studies, we anesthetized the dogs with pentobarbital and, with the reported methods (9), sequentially
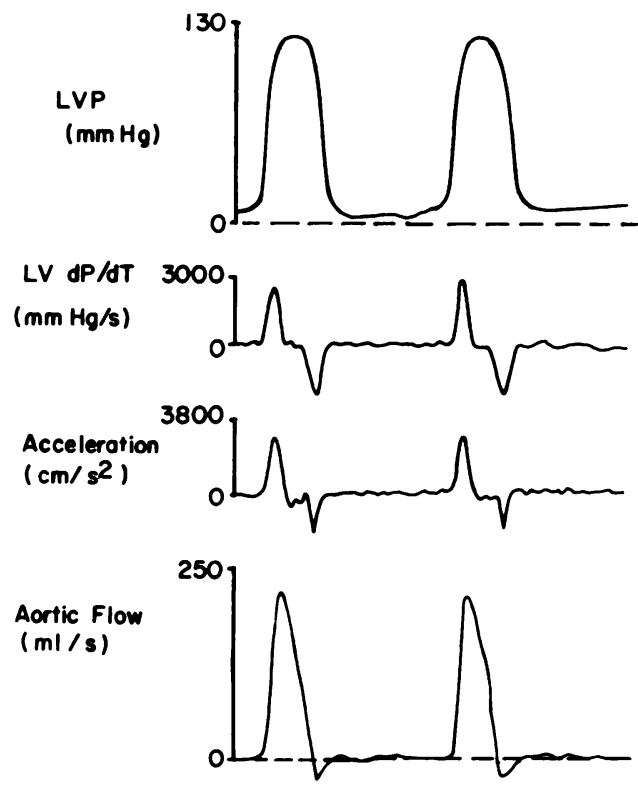

Figure 1 Control recordings obtained from a resting conscious dog. The simultaneous recordings of high fidelity left ventricular pressure (LVP), derivative of left ventricular pressure (LV $d P / d T)$, derivative of ascending aortic blood flow velocity (acceleration), and ascending aortic blood flow are shown. 
measured skeletal muscle content of phosphorus and serum inorganic phosphorus concentration. This was done to ascertain the level of peripheral phosphorus stores. Base-line phosphorus measurements were determined at the end of the postsurgical recovery period before phosphorus depletion was induced, repeated after 3 and 5 wk of phosphorus restriction, and again after 1 and 3 wk of phosphorus repletion. Blood samples were also collected at the same times to measure hematocrit, hemoglobin, creatine phosphokinase, electrolytes, $\mathrm{pH}$, and $\mathrm{PCO}_{2}$. Erythrocyte ATP concentration was also measured kit 35-UV (Sigma Chemical Co., St. Louis, Mo.) Body weight was monitored weekly. Body temperatures were obtained rectally at the time of skeletal muscle biopsies. No histologic studies were obtained.

Statistical analysis. Variables were measured on all six dogs on day 0 (control), after 3 and 5 wk of depletion (days 21 and 35), and after 1 and 3 wk of repletion (days 42 and 56). To know whether any of the variables changed significantly over the 56-day period, we used a two-way analysis of variance for each variable (18). The results in Table I list the significance level of the $F$ test comparing the five time periods. Second, to compare the time periods to control for significant results $(P<0.01)$, we performed Dunnett's multiple range test (19). All data presented are means \pm SE.

\section{RESULTS}

Clinical effects of phosphate depletion. Initially, the dogs would consume all of their diet in a few minutes. During the last 2 wk of phosphorus depletion, however, four of the six dogs required gavage feeding to ensure complete intake of the diet. During the repletion period, their anorexia disappeared rapidly, and they again voluntarily consumed their

TABLE I

Results of Analysis of Variance for Testing Time Effect

\begin{tabular}{ll}
\hline \multicolumn{1}{c}{ Variable } & Significance level \\
\hline Serum & \\
sodium & 0.06 \\
potassium & 0.28 \\
chloride & 0.13 \\
calcium & 0.06 \\
magnesium & 0.73 \\
creatine phosphokinase & 0.29 \\
phosphorus & 0.0001 \\
Blood & \\
pH & 0.71 \\
Pco & 0.91 \\
Erythrocyte & \\
ATP & 0.0001 \\
Skeletal muscle & \\
phosphorus content & 0.0001 \\
Cardiac function & \\
heart rate & 0.33 \\
stroke volume & 0.0002 \\
mean flow & 0.0001 \\
peak velocity & 0.0001 \\
maximum acceleration & 0.0001 \\
Max $d P / d T$ & 0.0001 \\
\hline & \\
\hline &
\end{tabular}

entire ration. In addition, after 5 wk of phosphorus depletion, five dogs showed some decrease in spontaneous activity but otherwise appeared normal. Weights did not significantly differ: day $0,21.3 \pm 0.9$; day $35,22.0 \pm 0.7$; and day $56,22.1 \pm 0.7$. Rectal temperatures taken at time of muscle biopsy also were not significantly different from control at the different time periods throughout the study.

Serum electrolytes, creatine phosphokinase, hematocrit, and blood gases. After 3 and 5 wk of phosphorus depletion, there was no significant difference in serum $\mathrm{Na}^{+}, \mathrm{K}^{+}, \mathrm{Cl}^{-}, \mathrm{Mg}^{++}, \mathrm{Ca}^{++}$, and creatine phosphokinase concentrations. Serum phosphorus, however, declined significantly, from an average control value of $5.1 \pm 0.1$ to $1.0 \pm 0.1 \mathrm{mg} / \mathrm{dl}(P<0.01)$ after 3 wk and to $0.9 \pm 0.1 \mathrm{mg} / \mathrm{dl}(P<0.01)$ after $5 \mathrm{wk}$. A slight, but significant, decrease was also noted in hematocrit $46 \pm 2$ to $41 \pm 2(P<0.01)$ and hemoglobin $15.5 \pm 1.0$ to $13.6 \pm 1.0 \mathrm{~g} / \mathrm{dl}(P<0.01)$ after $5 \mathrm{wk}$. After phosphorus repletion the hematocrit and hemoglobin returned toward control values. There was no statistical difference after 3 and $5 \mathrm{wk}$ in blood $\mathrm{pH}$ or $\mathrm{PCO}_{2}$.

Erythrocyte ATP. $3 \mathrm{wk}$ after phosphorus depletion erythrocyte ATP had decreased significantly, from a mean control value of $2.3 \pm 0.1 \mu \mathrm{M} / \mathrm{g}$ to $1.3 \pm 0.2 \mu \mathrm{M} / \mathrm{g}$ of hemoglobin $(P<0.01)$. After $5 \mathrm{wk}$, values were $0.8 \pm 0.2 \mu \mathrm{M} / \mathrm{g}$ of hemoglobin $(P<0.01)$. With repletion, erythrocyte ATP values increased after $1 \mathrm{wk}$ to $1.25 \mu \mathrm{M} / \mathrm{g}(P<0.01)$ and after $3 \mathrm{wk}$ to $2.2 \pm 0.1 \mu \mathrm{M} / \mathrm{g}$, which was not statistically different from control values.

Skeletal muscle composition. After 3 wk of phosphorus depletion, total muscle phosphorus content had decreased $\cong 13 \%$, from $28.0 \pm 0.2$ to $24.9 \pm 0.2(P<0.01)$, and by $5 \mathrm{wk} \cong 19 \%$ to $22.6 \pm 0.5(P<0.01)$. With repletion, all values returned toward control values.

Cardiac function studies. Table II shows the effects of phosphorus depletion and repletion on cardiac function determinants. Although measurements were made weekly after recovery from surgery, only values during control (day 0), early (day 21), and late (day 35) phosphorus depletion and early (day 42) and late (day 56) phosphorus repletion periods are given. Weekly measurements, however, from one dog are shown in Fig. 2. Similar changes were observed in the remaining five dogs. During phosphorus depletion heart rate did not change significantly; however, average stroke volume and mean ascending aortic blood flow decreased 29\% $(P<0.01)$ and $24 \%(P$ $<0.01$ ), respectively. During phosphorus repletion both variables returned to their control values.

All three indices of myocardial contractility, maximum ascending aortic blood flow velocity and acceleration, and Max $d P / d T$ showed evidence of myocardial depression during phosphorus depletion that was reversible during the period of repletion (Table II). 
TABLE II

Cardiac Function Studies

\begin{tabular}{|c|c|c|c|c|c|c|c|c|}
\hline & Day & & Heart rate & $\begin{array}{c}\text { Stroke } \\
\text { volume }\end{array}$ & $\begin{array}{l}\text { Mean } \\
\text { flow }\end{array}$ & $\begin{array}{c}\text { Peak } \\
\text { velocity }\end{array}$ & $\begin{array}{l}\text { Maximum } \\
\text { acceleration }\end{array}$ & $\begin{array}{c}\operatorname{Max} \\
d P / d T\end{array}$ \\
\hline & & & beats/min & $m l$ & $\mathrm{mlls}$ & $\mathrm{cm} / \mathrm{s}$ & $\mathrm{cm} / \mathrm{s}^{2}$ & $m m ~ H g / s$ \\
\hline $\begin{array}{l}\text { Control } \\
n=6\end{array}$ & 0 & $\begin{array}{l}\text { Mean } \\
\pm \text { SE }\end{array}$ & $\begin{array}{r}104 \\
\pm 9\end{array}$ & $\begin{array}{r}24 \\
\pm 2\end{array}$ & $\begin{array}{r}41 \\
\pm 3\end{array}$ & $\begin{array}{r}121 \\
\pm 12\end{array}$ & $\begin{array}{l}4,630 \\
\pm 313\end{array}$ & $\begin{array}{l}2,582 \\
\pm 347\end{array}$ \\
\hline $\begin{array}{l}\text { Early } \mathrm{PO}_{4} \\
\text { deficiency }\end{array}$ & 21 & $\begin{array}{l}\text { Mean } \\
\pm \mathrm{SE}\end{array}$ & $\begin{array}{r}112 \\
\pm 5\end{array}$ & $\begin{array}{r}19 \\
\pm 2\end{array}$ & $\begin{array}{r}36 \\
\pm 2\end{array}$ & $\begin{array}{r}108 \\
\pm 10\end{array}$ & $\begin{array}{l}4,153 \\
\pm 354\end{array}$ & $\begin{array}{l}2,308 \\
\pm 277\end{array}$ \\
\hline$n=6$ & & $P$ & NS & $<0.01$ & $<0.01$ & $<0.01$ & $<0.01$ & $<0.01$ \\
\hline $\begin{array}{l}\text { Late } \mathrm{PO}_{4} \\
\text { deficiency }\end{array}$ & 35 & $\begin{array}{l}\text { Mean } \\
\pm \text { SE }\end{array}$ & $\begin{array}{r}115 \\
\pm 9\end{array}$ & $\begin{array}{r}17 \\
\pm 2\end{array}$ & $\begin{array}{r}31 \\
\pm 3\end{array}$ & $\begin{array}{r}98 \\
\pm 7\end{array}$ & $\begin{array}{l}3,817 \\
\pm 346\end{array}$ & $\begin{array}{l}2,120 \\
\pm 297\end{array}$ \\
\hline$n=6$ & & $P$ & NS & $<0.01$ & $<0.01$ & $<0.01$ & $<0.01$ & $<0.01$ \\
\hline $\begin{array}{c}\text { Early } \mathrm{PO}_{4} \\
\text { repletion }\end{array}$ & 42 & $\begin{array}{l}\text { Mean } \\
\pm \mathrm{SE}\end{array}$ & $\begin{array}{r}116 \\
\pm 8\end{array}$ & $\begin{array}{r}21 \\
\pm 3\end{array}$ & $\begin{array}{r}39 \\
\pm 4\end{array}$ & $\begin{array}{r}111 \\
\pm 7\end{array}$ & $\begin{array}{l}4,179 \\
\pm 326\end{array}$ & $\begin{array}{l}2,505 \\
\pm 337\end{array}$ \\
\hline$n=6$ & & $P$ & NS & NS & NS & NS & $<0.01$ & NS \\
\hline $\begin{array}{l}\text { Late } \mathrm{PO}_{4} \\
\text { repletion }\end{array}$ & 56 & $\begin{array}{l}\text { Mean } \\
\pm \text { SE }\end{array}$ & $\begin{array}{r}117 \\
\pm 6\end{array}$ & $\begin{array}{r}22 \\
\pm 2\end{array}$ & $\begin{array}{r}42 \\
\pm 3\end{array}$ & $\begin{array}{r}123 \\
\pm 11\end{array}$ & $\begin{array}{l}4,446 \\
\pm 329\end{array}$ & $\begin{array}{l}2,616 \\
\pm 315\end{array}$ \\
\hline$n=6$ & & $P$ & NS & NS & NS & NS & NS & NS \\
\hline
\end{tabular}

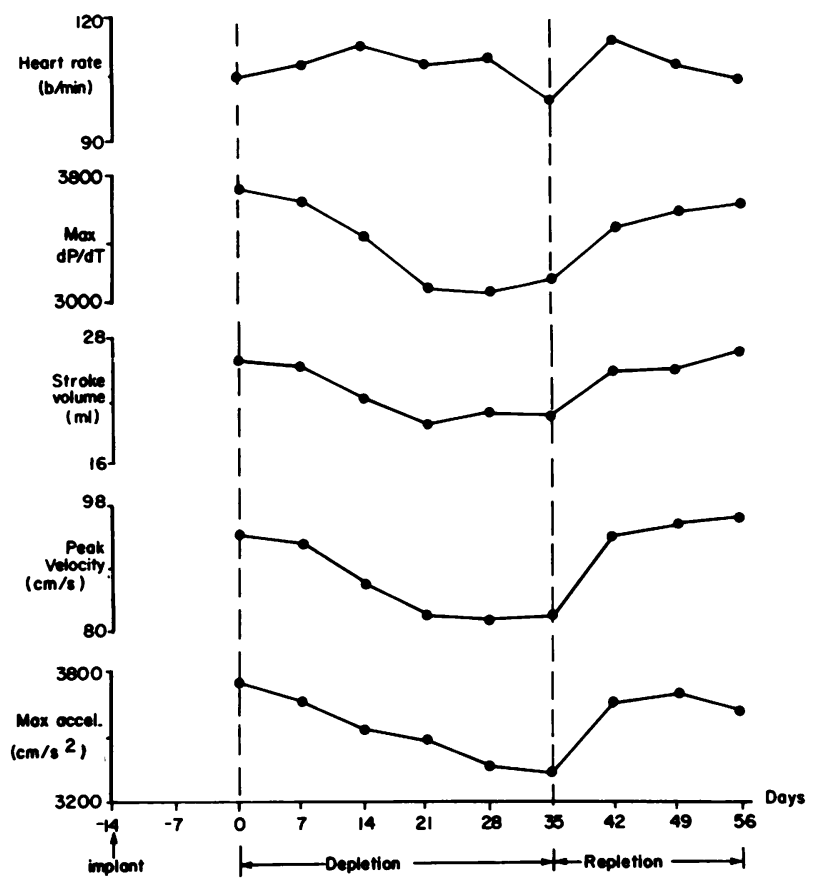

FIGURE 2 Effects in one dog of phosphorus depletion (35 days) and repletion (21 days) on heart rate, beats per minute (b/min), Max $d P / d T$, stroke volume, and maximum ascending aortic blood flow velocity and acceleration. 14 days were allowed for postsurgical recovery before beginning the study (day 0). Recordings were obtained weekly thereafter for the duration of the study.
Average Max $d P / d T$ decreased a total of $18 \%$ $(P<0.01)$ during depletion, and average maximum velocity and acceleration declined $19 \%(P<0.01)$ and $18 \%(P<0.01)$, respectively. Measurements of maximum blood flow acceleration from all six individual dogs during control, early, and late phosphorus depletion periods and early and late repletion periods are shown in Fig. 3. In all six dogs this variable decreased

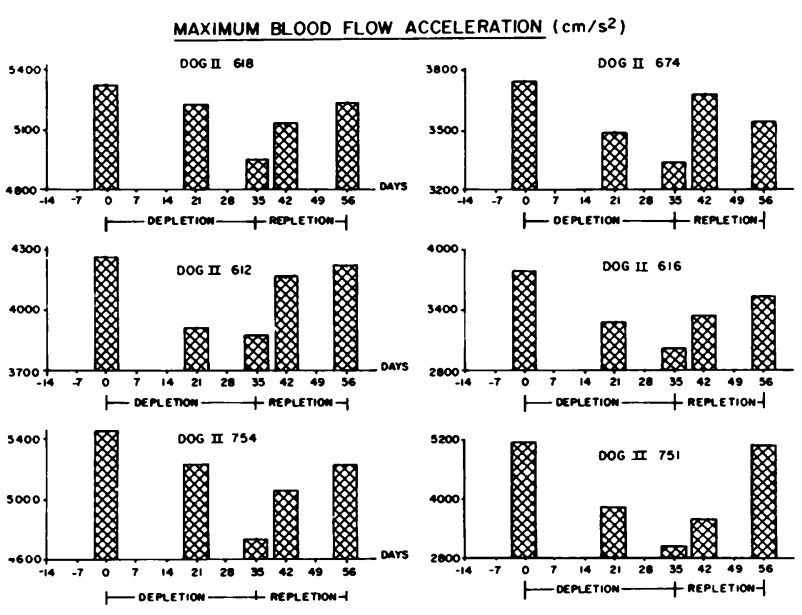

FIGURE 3 Histograms of maximum ascending aortic blood flow acceleration obtained from all six dogs during control (day 0), early (day 21), and late (day 35) phosphorus depletion and early (day 42) and late (day 56) phosphorus repletion periods. 

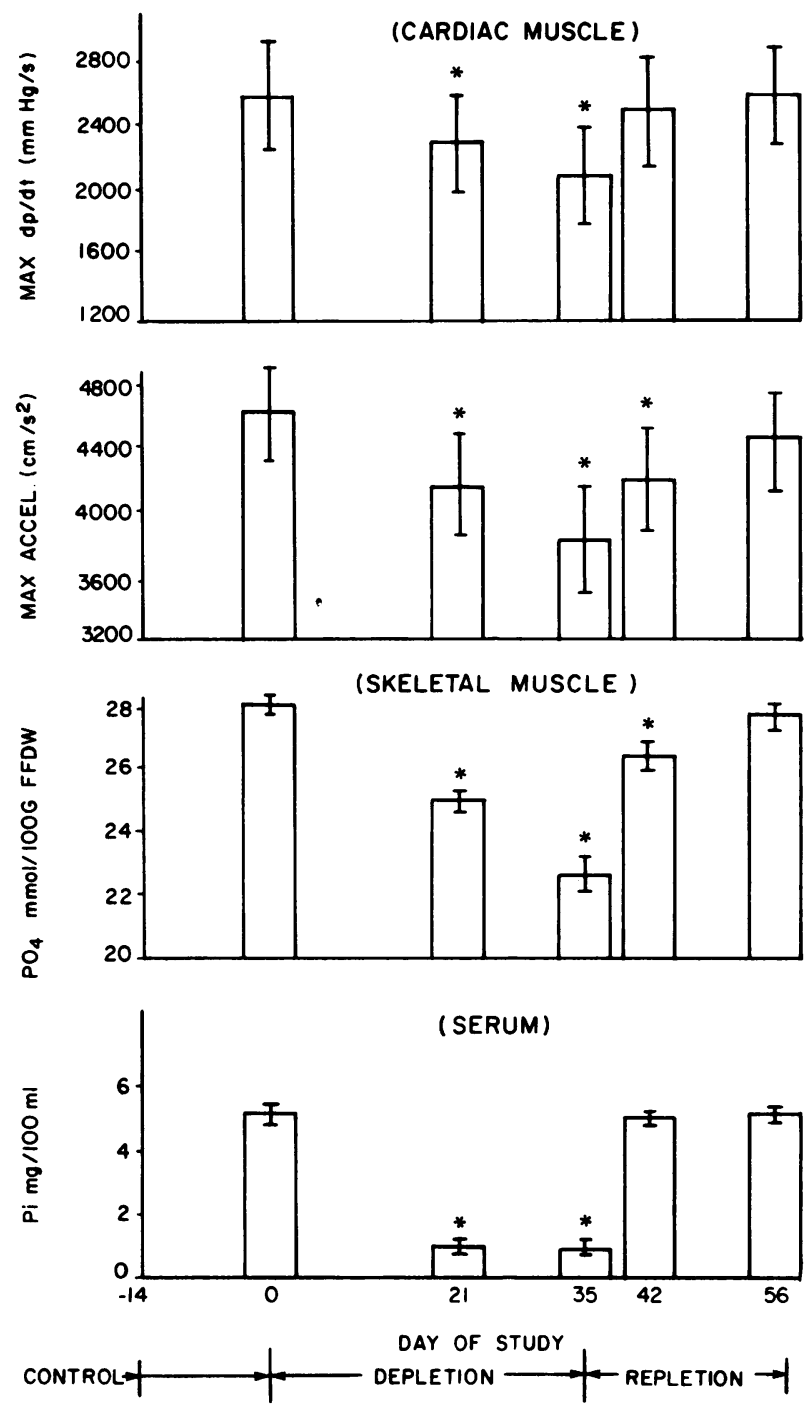

FIGURE 4 Relationship between Max $d P / d T$, maximum ascending aortic blood flow acceleration, skeletal muscle phosphorus content $\left(\mathrm{PO}_{4}\right)$, and serum inorganic phosphorus concentration ( $\mathrm{Pi}$ ) during control (day 0 ), phosphorus depletion (days 21 and 35), and phosphorus repletion (days 42 and 56) $(*, P<0.01)$.

during phosphorus depletion and returned to control values during repletion. Similar changes were also observed in maximum blood flow velocity and Max $d P / d T$ in each animal.

Comparison of cardiac function determinants, serum phosphorus, and muscle phosphorus content. The relationship between Max $d P / d T$, maximum blood flow acceleration, muscle phosphorus content, and serum phosphorus concentration during control, phosphorus depletion, and repletion periods is illustrated in Fig. 4. As serum phosphorus and total muscle content of phosphorus decreased, there was a concomitant drop in Max $d P / d T$ and maximum acceleration, indicating a depression in myocardial contractility. During repletion, with the return of serum phosphorus concentration and muscle phosphorus content to normal, myocardial contractility also returned to control values as reflected by changes in Max $d P / d T$ and maximum acceleration.

\section{DISCUSSION}

Mean ascending aortic blood flow and left ventricular stroke volume decreased in all animals during phosphorus depletion, whereas heart rate remained essentially unchanged $(P=N S)$. In addition, maximum velocity and acceleration of aortic root blood flow and Max $d P / d T$ decreased significantly during phosphorus depletion in all animals. These changes, in maximum acceleration and Max $d P / d T$, which are indicative of myocardial depression and independent of preload, afterload, and heart rate $(11,12,20-24)$, paralleled the degree of phosphorus depletion (Fig. 4). This suggested that the observed changes in myocardial performance were a result of changes in phosphorus balance and not left ventricular volume, resistance to left ventricular ejection, or ventricular rate.

The use of velocity and acceleration of ascending aortic blood flow to assess left ventricular function was first suggested by Rushmer (25). Noble et al. (11) showed in conscious dogs that coronary artery occlusion caused a decrease in maximum acceleration, although cardiac output and arterial pressure remained essentially unchanged. Furthermore, they showed that changes of posture, with the presumed associated changes in end-diastolic dimensions or preload, did not alter maximum acceleration. Similar observations were made in conscious dogs by Kezdi et al. (20) during gradual coronary artery occlusion to induce myocardial infarction. Following this lead, other investigators (21) have used maximum acceleration to study the depressant effects of anesthetic agents on myocardial performance.

Considerable evidence also indicates that in conscious dogs maximum left ventricular $d P / d T$ is a reliable index of the inotropic state of the myocardium $(12,22)$. These studies showed an increase in Max $d P / d T$ with the administration of positive inotropic agents and a decrease with cardiac depressant drugs. This variable was only minimally influenced by changes in preload (volume infusion), afterload (phenylephrine administration), and heart rate (right atrial pacing). In a recent study of problems associated with the use of indices of myocardial contractility, Van Den Bos et al. (23) found in conscious dogs that both maximum blood flow acceleration and Max $d P / d T$ 
were less influenced than were other contractile indices, by changes in preload and afterload. In our studies, maximum blood flow velocity and acceleration decreased $19 \%(P<0.01)$, and $18 \%(P<0.01)$, respectively, with 5 wk of phosphorus depletion. During this same period Max $d P / d T$ decreased $18 \%(P<0.01)$ and average stroke volume decreased $29 \%(P<0.01)$.

It appears evident, therefore, from these studies that phosphorus depletion depresses myocardial performance and is reversible with phosphorus repletion. Although we did not attempt to ascertain the mechanism of the decrease in myocardial performance with phosphorus depletion, a defect in the production or use of the high energy phosphate, ATP, known to be important to the process of contraction (26) is a likely candidate. This is especially true when one considers that depleted stores of ATP have been identified in all other cell sites studied in hypophosphatemic human subjects or animals $(2-5,27,28)$.

Another possibility is that phosphorus depletion impairs $\mathrm{Ca}^{++}$metabolism. Because $\mathrm{Ca}^{++}$is essential at several points in the sequence of muscle activation and relaxation, phosphorus depletion could impair contractility by either producing a deficit in available intracellular $\mathrm{Ca}^{++}$or alter its intracellular distribution or both (29). There was no significant difference in serum $\mathrm{Ca}^{++}$; however, a decrease in inorganic phosphate affects both the uptake of $\mathrm{Ca}^{++}$by the cell as well as its intracellular distribution (30). In addition, in certain animal models, a decrease in cardiac contractility has been associated with an abnormality of $\mathrm{Ca}^{++}$pumping by the sarcoplasmic reticulum (31). This function is dependent upon both ATP, which requires the availability of adequate stores of inorganic phosphate for resynthesis, and $\mathrm{Ca}^{++}$-activated ATPase, which also could be affected by phosphate depletion.

\section{ACKNOWLEDGMENTS}

Special thanks for the expert secretarial and editorial assistance of Alice Cullu and her staff.

This work was supported in part by the Medical Research Service of the Veterans Administration.

\section{REFERENCES}

1. Rajan, K. S., R. Levinson, and C. M. Leevy. 1973. Hepatic hypoxia secondary to hypophosphatemia. Clin. Res. 21: 521A. (Abstr.)

2. Travis, S. F., H. J. Sugerman, R. L. Ruberg, S. J. Dudrick, M. D. Papadopoulos, L. D. Miller, and F. A. Oski. 1971. Alteration of red cell glycolytic intermediates and oxygen transport as a consequence of hypophosphatemia in patients receiving intravenous hyperalimentation. $N$. Engl. J. Med. 285: 763-768.

3. Jacob, H. S., and T. A. Amsden. 1971. Acute hemolytic anemia with rigid cells in hypophosphatemia. N. Engl. J. Med. 285: 1446-1450.

4. Craddock, P. R., Y. Yawata, L. VanSanten, S. Gilberstadt,
S. Silvis, and H. S. Jacob. 1974. Acquired phagocyte dysfunction. A complication of the hypophosphatemia of parenteral hyperalimentation. N. Engl. J. Med. 290: 1403-1407.

5. Yawata, Y., R. P. Hebbel, S. Silvis, R. Howe, and H. Jacob. 1974. Blood cell abnormalities complicating the hypophosphatemia of hyperalimentation: erythrocyte and platelet ATP deficiency associated with hemolytic anemia and bleeding in hyperalimented dogs. J. Lab Clin. Med. 84: 643-653.

6. Goldfarb, S., G. R. Westby, M. Goldberg, and Z. S. Agus. 1977. Renal tubular effects of chronic phosphate depletion. J. Clin. Invest. 59: 770-779.

7. Mordchai, R., and M. Robson. 1976. Proximal myopathy caused by iatrogenic phosphate depletion. JAMA (J. Am. Med. Assoc.). 236: 1380-1381.

8. Lotz, M., E. Zisman, and F. C. Bartter. 1968. Evidence for a phosphorus depletion syndrome in man. N. Engl. J. Med. 278: 409-415.

9. Fuller, T. J., N. W. Carter, C. Barcenas, and J. P. Knochel. 1976. Reversible changes of the muscle cell in experimental phosphorus deficiency. J. Clin. Invest. 57: 10191024.

10. O'Connor, L. R., W. S. Wheeler, and J. E. Bethane. 1977. Effect of hypophosphatemia on myocardial performance in man. N. Engl. J. Med. 297: 901-903.

11. Noble, M. I. M., D. Trenchard, and A. Guz. 1966. Left ventricular ejection in conscious dogs. Circ. Res. 19: 139-147.

12. Barnes, G. E., V. S. Bishop, L. D. Horwitz, and R. L. Kaspar. 1973. The maximum derivatives of left ventricular pressure and transverse internal diameter as indices of the inotropic state of the left ventricle in conscious dogs. J. Physiol. (Lond.). 235: 571-590.

13. Khouri, E. M. 1973. Implantation of flow transducers on the left coronary artery and central aorta. In Chronically Implanted Cardiovascular Instrumentation. E. P. McCutcheon, editor. Academic Press, Inc., New York. 257262.

14. Stone, H. L. 1973. Implantation of solid state pressure transducers. In Chronically Implanted Cardiovascular Instrumentation. E. P. McCutcheon, editor. Academic Press, Inc., New York. 229-233.

15. McDonald, D. A. 1974. Blood Flow in Arteries. The Williams \& Wilkins Co., Baltimore, 2nd edition. 259.

16. McCutcheon, E. P., and J. M. Evans. 1973. Evaluation of miniature pressure transducers. In Chronically Implanted Cardiovascular Instrumentation. E. P. McCutcheon, editor. Academic Press, Inc., New York. 21-33.

17. Gersh, B. J., C. E. W. Hahn, and C. Prys-Roberts. 1971. Physical criteria for measurement of left ventricular pressure and its first derivative. Cardiovasc. Res. 5: 3240.

18. Zar, J. H. 1974. Biostatistical Analysis. Prentice-Hall, Inc., Englewood Cliffs, N. J. 130-181.

19. Dunnett, C. W. 1955. A multiple comparison procedure for comparing several treatments with a control. J. Am. Stat. A. 50: 1096-1121.

20. Kezdi, P., E. L. Stanley, W. J. Marshall, Jr., and R. K. Kordenal. 1969. Aortic flow velocity and acceleration as an index of ventricular performance during myocardial infarction. Am. J. Med. Sci. 257: 61-71.

21. Eisele, J. H., D. Trenchard, J. Stubbs, and A. Guz. 1969. The immediate cardiac depression by anesthetics in conscious dogs. Br. J. Anaesth. 41: 86-93.

22. Mahler, F., J. Ross, Jr., R. A. O'Rourke, and J. W. Covell. 1975. Effects of changes in preload, afterload and ino- 
tropic state on ejection and isovolumic phase measures of contractility in the conscious dog. Am. J. Cardiol. 35: $626-634$.

23. Van Den Bos, G. C., G. Elzinga, N. Westerhof, and M. I. M. Noble. 1973. Problems in the use of indices of myocardial contractility. Cardiovasc. Res. 7: 834-848.

24. Quinones, M. A., W. H. Gaasch, and J. K. Alexander. 1976. Influence of acute changes in preload, afterload, contractile state and heart rate on ejection and isovolumic indices of myocardial contractility in man. Circulation. 53: 293-302.

25. Rushmer, R. F. 1964. Initial ventricular impulse. A potential key to cardiac evaluation. Circulation. 29: 268-283.

26. Katz, A. M. 1975. Congestive heart failure: role of altered cellular control. N. Engl. J. Med. 293: 1184-1191.

27. Yawata, Y., P. R. Craddock, R. Hebbel, R. Howe, S. S.
Luis, and H. Jacob. 1974. Hyperalimentation hypophosphatemic hematologic-neurologic dysfunction due to ATP depletion. Clin. Res. 21: 729A. (Abstr.)

28. Kreusser, W. J., K. Kurokawa, and S. G. Massry. 1977. Effects of phosphate depletion (PD) on levels of inorganic phosphorus $(\mathrm{Pi})$ and adenine nucleotides of renal cells. Clin. Res. 25: 126A. (Abstr.)

29. Chidsey, C. A. 1974. Calcium metabolism in the normal and failing heart. In The Myocardium: Failure and Infarction. E. Braunwald, editor. H. P. Publishing Co., Inc., New York 37-47.

30. Rasmussen, H. 1971. Ionic and hormonal control of calcium homeostasis. Am. J. Med. 50: 567-588.

31. Suko, J., J. H. K. Vogel, and C. A. Chidsey. 1970. Intracellular calcium and myocardial contractility. Circ. Res. 27: 235-247. 